\title{
Psychological and nutritional factors in disturbances of menstrual function and ovulation
}

\author{
G. F. M. RuSSELL \\ M.D., F.R.C.P., F.R.C.P. Ed., D.P.M. \\ Professor of Psychiatry, \\ Royal Free Hospital School of Medicine, London, W.C.1
}

THE influence of psychological factors on menstrual function should be considered under two headings:

(1) The effects on the subject of upheavals occurring in the outside world.

(2) The special make-up of the individual who may have a greater or lesser degree of sensitivity to these upheavals.

The second of these factors is always more difficult to assess; in extreme instances it can be neglected. For example, if the emotional upheaval is of considerable magnitude, we may expect most persons to react adversely to it. Hence, the study of major commotions is one way of assessing the effects of psychological upsets on menstruation without having to pay the same regard to the variable vulnerability of different women.

\section{Studies in time of war}

Times of war have provided appropriate conditions for the study of the psychological precipitants of amenorrhoea, but there were often two sources of difficulty: psychological stresses seldom occurred in the absence of food deprivation, and circumstances were such that only simple clinical observations could be made. It was seldom possible to carry out measurements of the subjects' mental or endocrine status; neither was it possible to make comparisons with control groups.

Nevertheless, war-time catastrophes provided ample evidence that sudden emotional shocks readily brought about a cessation of menstruation in previously normal women. These catastrophes varied from air raids (Loeser, 1943; Whiteacre \& Barrera, 1944), to internment (Whiteacre \& Barrera, 1944; Sydenham, 1946; Bass, 1947) and the threat of extermination (Bass, 1947). The frequency of the amenorrhoea thus induced often varied on the harshness of the conditions and the fear aroused in the victims. Thus, Bass recorded the frequency of amenorrhoea among Jewish women deported from France to the concentration camp of Theresienstadt. Those women who faced the prospect of further deportation to the East and to the gas chambers of Auschwitz showed a rate twice as high $(54 \%)$ as those women who were appointed 'administrators' to the concentration camp and who had less reason to fear for their lives $(25 \%)$. Most observers attach greater importance to these psychological factors than to malnutrition in the arrest of menstruation in the victims of concentration camps (Horvath, Sellei \& Weisz, 1948; Drew, 1961).

Yet most accounts of war-time amenorrhoea concede that food deprivation played a part in causing or perpetuating the arrest of menstruation. When malnutrition was prolonged it led to a fall in the birth rate, as during the hunger periods in Holland from the autumn of 1944 until May 1945.8 Menstruation was said to have ceased in $50 \%$ of urban women. The rate of conception fell as shown by a drop in the birth rate 9 months or 1 year later? (October 1945) to as low as one-third of the previous level obtaining in cities such as Rotterdam (Smith, 1947).

The interplay between emotional and nutritional factors was neatly analysed by Sydenham (1946) in her observations on interned civilians in Stanley Camp, Hong Kong, during the last war. Soon after internment, in December 1941, and kefore any loss of weight was apparent, menstruation ceased in $60 \%$ of the women whose periods had previously been regular. The reason must have been the emotional shock of the internment. However, the amenorrhoea persisted until December 1942 when most of these women menstruated again following the arrival of a shipment of tinned meat and an improvement in the food rations. In January 1944, there was a renewed shortage of meat and fish and, soon after, the prevalence of amenorrhoea rose again. After release in September 1945 most of these women resumed normal menstruation. It could therefore be concluded that both factorsfood shortage and emotional distress - were operative in causing amenorrhoea.

\section{Studies in time of peace}

Peace-time studies of an undernourished population in Mexico have been carried out by Zubiran, Gomez-Mont \& Laguna (1955). They confirmed 
that when the intake of calories and protein fell below a critical level, the frequency of amenorrhoea in young women rose as high as $50 \%$.

The study of amenorrhoea and infertility due to psychological disturbances is more difficult in the absence of war or large-scale disasters. There are three main sources of observations:

(1) The effects of identifiable emotional upheavals in 'normal' subjects.

(2) Patients with a frank psychiatric illness.

In them the emotional disturbance is part of an illness which may have resulted from outside stresses (a reactive illness), internal conflicts or a pathological process. In any of these cases the psychological and emotional symptoms are of such severity as to provide a disruptive influence on bodily functions such as menstruation which are thought to be vulnerable to emotional upheavals.

(3) Feeding disorders. (a) Patients with anorexia nervosa in whom amenorrhoea is a constant finding and (b) obese patients following a weight-reducing regime in whom menstruation may also become disturbed.

\section{(1) Sudden emotional upheavals}

Recent studies are but pale counterparts of the more dramatic war-time experiences. There are a few isolated case-reports of amenorrhoea arising through, for example, a fear of pregnancy (Loeser, 1943) but, on the whole, clinicians have had to be content with studying the effects on young girls of leaving home and going to a strange environment such as the armed services (Drillien, 1946; Sher, 1946), convents (Drew \& Stifel, 1968), or residential nursing schools (Osofsky \& Fisher, 1967). In spite of the rather minor nature of the upsets caused by these life-changes, relatively high incidences of amenorrhoea are reported in these women (6-22\%).

A study is currently being conducted by Dr J. Christie Brown (1972) with the aim of ascertaining whether disturbing events precede the cessation of menstruation in women referred to a gynaecological clinic for secondary amenorrhoea. By obtaining a control group of patients attending the same clinic for other reasons (e.g. cervical erosions), it is hoped to allow for irrelevant factors such as the tendency for patients with neurotic problems to seek medical treatment.

\section{(2) Psychiatric illness}

When the incidence of amenorrhoea in mental illness was reviewed by Gregory in 1957, relatively high rates were reported for the more severe illnesses (psychoses) such as schizophrenia $(74 \%)$, whereas affective disorders $(12 \%)$ and other neuroses $(11 \%)$ revealed lower rates. The one exception was anorexia nervosa with a $100 \%$ occurrence of amenorrhoea. The frequency of amenorrhoea in psychiatric illness seems now to be much lower than that reported by Gregory. He had already detected that depressed patients more often continued to menstruate regularly and this he attributed to improved methods of treatment for depressive illness. It is now difficult to find psychiatric patients who have developed amenorrhoea, even among schizophrenics, and this too may be the result of more effective treatment.

\section{(3) Feeding disorders}

(a) Anorexia nervosa. In contrast, patients with anorexia nervosa are now more frequently reported and there is evidence that they are seen more commonly in medical practice than, say, 30 years ago (Theander, 1970). Interest in these patients arises from the fact that, in addition to the constant finding of amenorrhoea and relative infertility, they usually display a marked psychiatric disorder that goes beyond their avoidance of food and fear of becoming fat. Whereas the feeding disorder and the emaciation are usually the most conspicuous clinical features in these patients, it is the cessation of menstruation which may be the first event in the onset of the illness or which may coincide with the onset of food refusal (Kay \& Leigh, 1954). The illness typically begins in a young girl a few months or years after puberty. Until then physical and emotional maturation seem to have progressed normally. When menstruation ceases, however, psychosexual regression occurs. The young woman may hitherto have shown a normal awakening interest in boys but she now loses this interest and breaks off any relationships she may have made. Even if the later course of the illness is favourable, a psychosexual immaturity often persists, marriage is relatively infrequent, frigidity is common and there is a reluctance to embark on a pregnancy. Thus, these patients show a reduced fertility due partly to the endocrine disturbance about to be described, but mainly to the psychosexual immaturity which tends to persist beyond the stage of recovery from the endocrine disorder. That recovery of fertility can occur is well substantiated by the follow-up studies of Dally (1969) and Theander (1970).

The features of the endocrine disorder in anorexia nervosa have been studied in the Metabolic Unit of the Maudsley Hospital on more than thirty patients, first with the co-operation of Dr J. A. Loraine of the MRC Clinical Endocrinology Research Unit, Edinburgh, and more recently with the help of Mr J. Newton and Dr C. Ryrie. The patients were treated essentially by nursing and dietary methods aimed at inducing weight gains of $10-20 \mathrm{~kg}$. Thus, the effects of correcting the malnutrition of these patients could be observed and an 
assessment made of those endocrine abnormalities which were simply the consequence of the severe loss of weight. Twenty-four-hour collections of urine were made serially over periods ranging from 50 to 120 days. In the main studies, total gonadotrophic activity (TGA) in the urine was measured by the bio-assay method of Loraine \& Brown (1959). This is a bio-assay which is non-specific in as much as it measures total gonadotrophic activity and cannot distinguish between the relative proportions of follicle-stimulating hormone (FSH) and luteinizing hormone ( $\mathrm{LH})$. The method is reliable however, and the results were expressed in terms of a standard (the Second International Preparation of Human Menopausal Gonadotrophin, IRP ${ }^{2} \mathrm{HMG}$ ). Urinary oestrogens were measured by the method of Brown (1955). More recent assays have been carried out by $\mathrm{Dr}$ Ryrie in Mr Newton's laboratory using a radio-immunoassay and measuring specifically $\mathbf{L H}$ activity (Wide, 1968).

(1) An early study, conducted on seven female patients, showed that when the patients were still undernourished, TGA in the urine was absent or very low. Similarly the three oestrogen fractions (oestradiol, oestriol and oestrone) were recovered in only small amounts. Following treatment and weight gain there was some variable increase in the urinary output of gonadotrophins and of the three oestrogen fractions, showing that the low levels of these hormones on admission were at least partly the result of the malnutrition. However, in spite of continuing the estimations over long periods-up to 4 months in some patients - there was no return of the cyclical variation of TGA. There is thus reason to believe that the rhythmic control of gonadotrophins is defective in anorexia nervosa-not as a sequel of malnutrition but as a more fundamental feature of the illness.

(2) In a further study at the Maudsley Hospital, fifteen patients were found to fall into two equal groups (Russell \& Beardwood, 1971):

(i) Seven patients in whom amenorrhoea occurred early during the course of the illness (coinciding with the onset of weight loss or even preceding it).

(ii) Seven patients in whom menstruation ceased only after a marked loss of weight and an interval of several weeks or months. (In one patient it was not possible to determine the onset of the amenorrhoea.)

The following observations were made as regards these two groups: the patients with amenorrhoea of early onset were found, on the whole, to have developed a more acute illness. Their weight loss was greater in spite of a shorter illness. Moreover, their TGA response to refeeding was less than in the group with amenorrhoea of late onset: it was found that the TGA response was inversely correlated with the weight loss suffered by these patients $(r=$ $-0.53 ; P<0.025)$.

Again, it was found that the return of cyclical variations in the levels of urinary gonadotrophins was not clearly related to body weight: there was a long delay after correction of the malnutrition. Among the fifteen patients in the second study, only four resumed menstruation during the 50-day period of refeeding (2) or shortly after (2). It appears, therefore, that although the malnutrition is probably the reason for the low urinary TGA, the failure of the rhythmical pattern of TGA in anorexia nervosa is probably due to other factors. These abnormalities may persist for a very long time as was shown by a 20-year-old patient who had returned to her normal weight for over 3 years but whose menstruation had not yet recovered; urinary TGA measured by the bio-assay method was low and there was no peak of $\mathrm{LH}$ as measured by a radio-immunoassay.

(b) Obesity. A study of three overweight patients treated with low-calorie diets over several months provided confirmatory evidence of the susceptibility of gonadotrophin activity to food restriction. In untreated obese patients menstrual function usually remains normal. As a result of being treated with low-calorie diets, however, menstruation ceasedo after two periods in one patient and after five periods in the other two patients: their weight losses amounted to 16,20 and $17 \mathrm{~kg}$ over the course of 87,120 and 146 days respectively. On measuring serial urinary TGA in these patients, it became clear that there was a gradual fall in the levels. Yet the rhythmical pattern of TGA persisted until the levels became undetectable, showing that weight reduction has its primary effect on the total level of urinary gonadotrophins rather than on the cyclical pattern of TGA.

\section{Conclusions}

The evidence has been presented that amenorrhoea can be induced both by emotional upheavals and by food restriction leading to weight loss. So far there have been no detailed and reliable studies of the urinary output of gonadotrophins in amenorrhoea of emotional origin, either caused by distressing events or associated with frank mental illness.

The hormonal studies in anorexia nervosa show that total gonadotrophic activity is abnormal: basal levels are low and cyclical fluctuations are absent. The study of obese patients treated with a weightreducing regimen suggests that food restriction and weight loss are more important in lowering the basal levels of total gonadotrophic activity, and less significant in influencing cyclical activity.

It has been shown in an earlier contribution (Donovan, 1971) that basal levels and cycles of 
TGA are controlled by different central nervous mechanisms, at least in some species of animals. The role of these mechanisms in amenorrhoea of emotional origin and that found in anorexia nervosa, must remain a matter for conjecture for the time being, but already hypotheses suggest themselves as a basis for further enquiry.

\section{References}

BAss, F. (1947) L'aménorrhee au camp de concentration de Terezin (Theresienstadt). Gynaecologia, 123, 211.

Brown, J.B. (1955) A chemical method for the determination of oestriol, oestrone and oestradiol in human urine. Biochemical Journal, 60, 185.

Christie Brown, J. (1972) Proceedings of the Third International Congress of Psychosomatic Medicine in Obstetrics and Gynaecology, 29 March-2 April 1971, London. Karger, Basel.

Dally, P. (1969) Anorexia Nervosa. Heinemann, London.

Donovan, B. (1971) The hypothalamic control of the menstrual cycle. Postgraduate Medical Journal, 47, 000.

DREW, F.L. (1961) The epidemiology of secondary amenorrhoea. Journal of Chronic Diseases, 14, 396.

Drew, F.L. \& Stifel, E.N. (1968) Secondary amenorrhoea among young women entering religious life. Obstetrics and Gynaecology, 32, 47.

Drillien, C.M. (1946) Study of normal and subnormal menstrual function in Auxiliary Territorial Service. Journal of Obstetrics and Gynaecology of the British Empire, $53,228$.

GreGORY, B.A.J.C. (1957) The menstrual cycle and its disorders in psychiatric patients. II. Journal of Psychosomatic Research, 2, 199.

Horvath, K., Sellei, C. \& Weisz, R. (1948) Beiträge zur Pathologie Symptomatologie und Therapie der kriegsbedingten Amenorrhoe. Gynaecologia, 125, 368.
KAY, D.W.K. \& LEIGH, D. (1954). The natural history, treatment and prognosis of anorexia nervosa, based on a study of 38 patients. Journal of Mental Science, 100, 411.

LOESER, A.A. (1943) Effect of emotional shock on hormone release and endometrial development. Lancet, i, 518.

LoRAINe, J.A. \& Brown, J.B. (1959) A method for the quantitative determination of gonadotrophins in the urine of non-pregnant human subjects. Journal of Endocrinology, $18,77$.

OsOFSKY, H.J. \& Fisher, S. (1967).Psychological correlates of the development of amenorrhoea in a stress situation. Psychosomatic Medicine, 29, 15.

Russell, G.F.M. \& Beardwood, C.J. (1971). Amenorrhoea in the feeding disorders: Anorexia nervosa and obesity. In the Proceedings of the 8th European Conference on Psychosomatic Research, held in Knokke, Belgium (May 1970). Psychotherapy and Psychosomatics. (In press.)

Sher, N. (1946) Causes of delayed menstruation and its treatment; an investigation in the Women's Auxiliary Service. British Medical Journal, 1, 347.

Sмiтh, C.A. (1947) Effects of maternal undernutrition upon the newborn infant in Holland (1944-45). Journal of Pediatrics, 30, 229.

Sydenham, A. (1946) Amenorrhoea at Stanley Camp, Hong Kong, during internment. British Medical Journal, 2, 159.

TheANDER, S. (1970) Anorexia nervosa. A psychiatric investigation of ninety-four female patients. Acta Psychiatrica Scandinavica, Suppl. 214.

WhiteACRE, F.E. \& BARRERA, B. (1944) War amenorrhoea. Journal of the American Medical Association, 124, 399.

WIDE, L. (1968) Immunological determinations of human gonadotrophins. In: Scientific Foundations of Obstetrics and Gynaecology. Heinemann, London.

Zubiran, S., Gomez-Mont, F. \& Laguna, J. (1955). Endocrine disturbances and their dietetic background in the undernourished in Mexico. Annals of Internal Medicine, 42, 1259. 